\title{
Entrevista com Josildeth Gomes Consorte: os 60 anos do Programa de Pesquisas Sociais do Estado da Bahia e Universidade de Columbia
}

\author{
entrevistadores: Érika Figueiredo, Isabela Oliveira, Janaína Damasceno
}

Esta entrevista é parte do especial Estudos de Comunidade, que compóe este número da revista Cadernos de Campo. O especial apresenta artigos e depoimentos que fizeram parte do evento "Constituindo um campo": estudos de comunidade e o desenvolvimento das ciências sociais no Brasil (1940-1960), realizado na Faculdade de Filosofia, Letras e Ciências Humanas da USP, em setembro de 2009. Uma das convidadas foi justamente Josildeth Gomes Consorte, que na impossibilidade de comparecer ao evento para dar seu depoimento, nos concedeu esta entrevista em 11 de novembro de 2009.

A antropóloga Josildeth Gomes Consorte é baiana, de Salvador, e nasceu em 21 de junho de 1930. Em 1947, recebeu seu primeiro diploma como professora primária pelo Instituto Normal da Bahia, atual ICEIA (Instituto Central de Educação Isaías Alves). Em 1949, ingressou no curso de Geografia e História da Universidade da Bahia, atual UFBA, onde concluiu seu bacharelado no ano de 1951. Durante o primeiro ano de sua graduação, em 1949, foi convidada por Thales de Azevedo para participar do que viria a ser chamado "Projeto Columbia University/ Estado da Bahia", o Programa de Pesquisas Sociais Estado da Bahia - Columbia University. Josildeth foi uma das primeiras integrantes do Programa, sendo encarregada de auxiliar nos preparativos para a realização das pesquisas que teriam lugar a partir do ano seguinte. E em 1950, há exatamente 60 anos, Josildeth partiu para sua primeira experiência de trabalho de campo na Chapada Diamantina, uma das regióes escolbidas pelo

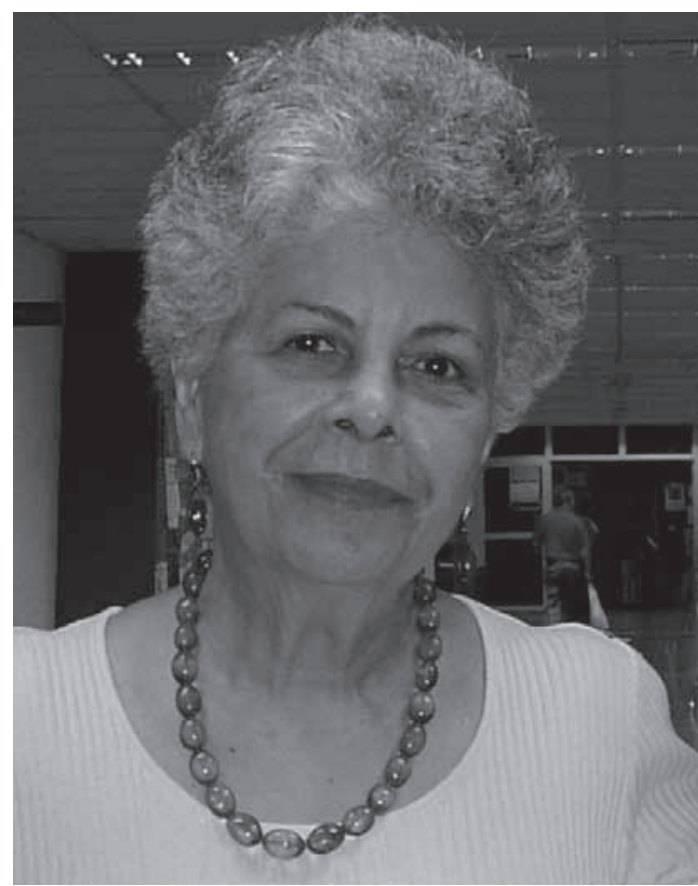

Programa, como auxiliar de Marvin Harris, responsável pelo estudo da comunidade de Rio de Contas. Ao todo, o Programa incluiria ainda três outras equipes, cada uma delas formada por um pós-graduando da Universidade de Columbia auxiliado por estudantes brasileiros de graduação. Tais pesquisas realizadas por iniciativa de Anisio Teixeira tiveram a coordenação dos professores Thales de Azevedo, Charles Wagley e Luiz Aguiar da Costa Pinto. Através desta experiência participava de uma das primeiras pesquisas de grande porte realizadas no Brasil no âmbito das ciências sociais, que no ano seguinte, em 1951, seria integrada ao projeto UNESCO sobre relaçóes raciais. Depois da participação neste projeto, Josi, como 
também é chamada, realizou entre 1952 e 1953 estudos complementares em Antropologia e Sociologia, ainda em nível de graduação na Escola de Sociologia e Politica de São Paulo. Estas atividades fizeram parte da preparação para seus estudos de pós-graduação nos Estados Unidos, realizados entre os anos de 1953 e 1955. Ao regressar ao Brasil, trabalhou no recém-criado CBPE (Centro Brasileiro de Pesquisas Educacionais) até 1961 e a seguir no INIC (Instituto Nacional de Imigração e Colonização). Neste meio tempo obteve no ano de 1957 sua licenciatura em Geografia e História na Universidade do Brasil, atual Federal do Rio de Janeiro. Em 1966 ingressou como professora de Antropologia na PUC/SP (Pontificia Universidade Católica de São Paulo), onde defendeu seu doutorado em Ciências Humanas na área de Antropologia em 1973. É professora titular da mesma universidade desde 1994 e entre seus temas de pesquisa mais recentes estão "identidade étnica", "sincretismo", e "religiosidade popular".

Cadernos de Campo: Vamos começar falando sobre o periodo de sua formação. Em um depoimento $^{1}$, a senhora afirma que sua aproximação com as ciências sociais se deu via Antropologia. Gostariamos de saber como foi esse encontro com a Antropologia, ainda no periodo de sua graduação em História e Geografia.

Josildeth Consorte: $\mathrm{O}$ encontro se deu através da disciplina de Introdução à Antropologia, lecionada pelo Dr. Thales [de Azevedo]. Eu nunca tinha ouvido falar em Antropologia, mas foi um deslumbramento. Era uma classe pequena e só de mulheres e ele conseguiu cativar a todas nós com o seu modo de ensinar Antropologia. Ele era um professor muito estimulante. Uma pessoa extremamente séria, devotada à Antropologia. Era médico e autodidata, como de modo geral eram todos os antropólogos naquela época. Foi com os seus encantos que ele conseguiu nos ensinar
Antropologia, que acabou se tornando a menina dos olhos do curso de Geografia e História. Interessante, não é? Entrei para o curso de Geografia e História e, de repente, me deparei com a Antropologia. Não era nem para eu ter feito Geografia e História. Geografia e História foi uma opção de aluna pobre que precisava trabalhar e que precisava saber o que ia fazer depois da faculdade, em termos de mercado de trabalho, filha como era de um mestre de obras e de uma bordadeira. Como normalista não tinha muitas opçóes ${ }^{2}$. Não podia fazer Ciências, não podia fazer Filosofia, não podia fazer Matemática. Podia fazer as Humanas, só as Humanidades. Podia fazer Letras, Pedagogia, Geografia e História. Então, e eu e Maria Raimunda [Guerra de Macedo], que era uma amiga inseparável, optamos por fazer Geografia e História porque assim teríamos muitas aulas para dar e poderíamos ajudar a família. Por isso fizemos Geografia e História e no primeiro ano encontramos o Dr. Thales e a Antropologia.

CC: Ainda na época de sua graduação, a senhora participa do chamado "Projeto Columbia University/ Estado da Bahia" [Programa de Pesquisas Sociais do estado da Bahia - Columbia University] que, atualmente está completando 60 anos. Como foi sua inserção?

JC: Outro dia falei disso lá em Vitória da Conquista. Fazia 60 anos que eu tinha passado por lá a caminho de Rio de Contas para fazer minha primeira participação numa pesquisa. Não era exatamente a primeira porque eu tinha trabalhado numa outra em Salvador, mas uma pesquisa de comunidade, dentro dos moldes clássicos, era a primeira. O Programa começou a se articular em 1949, quando o Dr. Anísio [Teixeira], então Secretário de Educação e Saúde do estado da Bahia convidou o Professor Wagley da Universidade de Columbia para fazer um pré-projeto de estudos so- 
bre a realidade social do estado da Bahia. No mesmo ano em que eu entrei na faculdade. No primeiro semestre, o Dr. Thales [de Azevedo] me procurou e perguntou se eu teria interesse em participar de um projeto com essas características. Eu delirei, e ele disse: "Bem, por enquanto está tudo muito nebuloso, mas assim que nós tivermos clareza em relação ao que vai acontecer, eu volto a falar com a senhora". Em meados do ano ele chegou e disse: "Está tudo certo. O projeto vai acontecer". Entre esse momento e junho de 1950 nós preparamos a chegada dos pesquisadores. Então de junho de 1949 a junho de 1950 eu fui auxiliar do Dr. Thales no levantamento de todo material, de todas as fontes, de tudo que foi possível reunir para subsidiar em Salvador esse trabalho, construindo uma infra-estrutura, levantando dados e todo tipo de fontes que a gente podia para que quando eles chegassem, encontrassem tudo à disposição. Esse foi o momento que antecedeu a chegada do professor Wagley e dos seus três doutorandos para começar o trabalho. No ano de 1949 nós, na Bahia, ficamos envolvidos com a montagem da infraestrutura enquanto eles, lá na Universidade de Columbia, se prepavam através de seminários, discutindo o Brasil, tentando aprofundar seu conhecimento da realidade do estado da Bahia. Foi um ano de seminários lá e de grandes preparativos aqui. Há 60 anos, pois nós estávamos preparando a chegada do pessoal. Eu acho que nunca três pós-graduandos [Marvin Harris, Harry Hutchinson e Benjamin Zimmerman] tiveram condiçôes de trabalho tão extraordinárias. $\mathrm{Na}$ verdade quatro, porque vieram três no primeiro ano, em 1950 e, um, no ano seguinte, o Tony Leeds [Anthony Leeds]. O programa se instalou efetivamente a partir de junho de 1950 envolvendo todos os pesquisadores, auxiliares e diretores. Houve um primeiro seminário em Salvador, depois do que os primeiros foram para o campo, lá fican- do até junho do ano seguinte. Com exceção de Benjamim Zimmerman que retornou antes deixando inconclusa a pesquisa em Monte Santo no Sertão semi-árido. Dentre os estudos preliminares feitos para esse projeto, está um estudo de áreas ecológico-culturais, realizado por Wagley, Thales e Costa Pinto, que vai dividir o estado da Bahia em seis áreas, a partir da qual algumas vão ser escolhidas para sede dos estudos: o Recôncavo, a Chapada Diamantina e o Sertão semi-árido. Na mesma ocasião a Escola de Sociologia e Política está embarcando em um projeto semelhante ao longo do Vale do São Francisco. É exatamente a mesma época. Em 1950, quando o Dr. Pierson, Octávio da Costa Eduardo e Levy Cruz fizeram a primeira viagem exploratória pelo São Francisco, nós já estávamos entrando em campo sabendo do projeto de Sáo Paulo. Curiosamente o Vale do São Francisco não entrou nas cogitações do projeto baiano. Inclusive, na divisão que o Thales, Costa Pinto e o Wagley fizeram das áreas ecológico-culturais, o Vale do São Francisco não aparece como uma área específica. $\mathrm{O}$ Vale do São Francisco aparece como parte do Planalto ocidental, da Chapada Diamantina, do Sertão semi-árido, atravessa regiōes, mas não é em si considerado uma região. Provavelmente em razão da perspectiva de cada grupo de como estava compreendendo aquela realidade. Uma coisa interessante é que também fazia parte do projeto paulista pesquisar uma comunidade tradicional e uma progressista. Só que eles acabaram não conseguindo recursos pra trabalhar duas comunidades dentro de cada região do Vale do São Francisco. Então, eles escolheram entre as cabeceiras e a foz cinco comunidades, não sei se eram as "mais atrasadas" ou as "mais desenvolvidas". Pelo depoimento do Tavinho [Octávio da Costa Eduardo] eu tenho a impressão de que eram as mais desenvolvidas. O Projeto da Bahia trabalhou com duas comunidades em cada uma 
das regióes escolhidas. Trabalhou mais com a comunidade tradicional, mas sempre visando compara-la com a comunidade em mudança. Porque o estudo todo tinha uma preocupação muito grande com mudança. Era um momento em que a ideia de tradicional/moderno, tradicional/progressista, essa visão dicotômica estava muito em voga pra entender o Brasil, um Brasil que iria sair desse formidável atraso para um imenso desenvolvimento, que se esperava acontecesse com o fim da Segunda Guerra. Juscelino Kubitschek que vem logo depois deste período é bem orientado por essa perspectiva. "Cinquenta anos em cinco". Quer dizer, o Brasil que vai deixar de ser um grande gigante adormecido. Esse momento coincidiu com o que se chamava de "passamento da sociedade tradicional”. Com o fim da Segunda Guerra Mundial, o mundo inteiro se dera conta de que não havia mais nenhum lugar que não tivesse sido tocado pelo conflito. $\mathrm{O}$ capitalismo tinha chegado a todo lugar, a sociedade ocidental tinha alcançado todo o ecúmeno. Consequentemente, o mundo tradicional estava fadado a desaparecer sob o impacto da presença dessa nova realidade. Esse é o grande momento dos estudos de desenvolvimento de comunidade, muito difundidos na área de serviço social. Momento em que os EUA vão injetar recursos mundo afora com a intenção de incentivar esse desenvolvimento.

\section{CC: E como o Programa de Pesquisas Sociais} do Estado da Bahia - Columbia University se constituiu?

JC: Como foi que esse projeto surgiu? Eu também estou em busca desta resposta. Porque a trajetória do Dr. Anísio [Anísio Teixeira] é na área de educação. Ele é um homem que tem uma formação filosófica muito boa que estava vocacionado para ser jesuíta, projeto com que a família não concordava e de que ele ele acabou tendo que abrir mão Foi para os Estados Unidos na década de 1920 tendo sido aluno de [John] Dewey e voltou de lá seduzido por essa educação inspirada por ele. É aí que começa sua paixão pela educação. Eu acho, e talvez não seja a única a pensar assim, que na verdade o que acabou acontecendo foi que todo aquele entusiasmo que ele tinha para se tornar jesuíta, toda aquela vocação de entrega como jesuíta ele acabou transferindo para a educação porque realmente este foi o projeto de sua vida. Eu gostaria muito de saber o que ele pensava a respeito do Brasil e do povo brasileiro. Nesse momento, nós estamos tentando entender um pouco mais sobre isso ${ }^{3}$. Qual era a visão de Brasil que ele tinha e qual era o papel que a educação poderia ou teria a representar dentro desse projeto. Eu acredito que ele apostava todas as fichas na educação porque acreditava que era a educação que iria transformar o Brasil em alguma coisa melhor. O que as ciências sociais teriam a contribuir neste sentido? Eu percebo em sua trajetória três momentos de imbricação com as ciências sociais $^{4}$ : o primeiro na década de 1930 no Distrito Federal [na época, Rio de Janeiro] quando ele foi Diretor Geral da Instrução e convidou Arthur Ramos (médico e antropólogo) para trabalhar com ele dirigindo o Serviço de Higiene e Ortofrenia. $\mathrm{Na}$ Introdução de "O Negro Brasileiro” há uma referência importante de Arthur Ramos sobre seu trabalho enquanto diretor deste setor. Nesta introdução ele faz a crítica da visão de Nina Rodrigues em relação ao negro brasileiro, atribuindo sua problemática não à sua incapacidade biológica e intelectual em relação à civilização ocidental, mas a questôes ligadas á esfera da cultura. Sendo um problema cultural ele poderia ser superado, não é? A questáo era de quem iria cumprir o papel de civilizá-lo. Segundo Arthur Ramos era fundamental para esta obra de civilização remover todas as suas crendices e superstiçóes, promovendo uma revolução intersticial pro- 
funda que eliminasse essas amarras, um papel que caberia à educação. Fica muito claro no pensamento do autor que o problema do negro era mover-se num universo mágico, que era aí que residia a fonte das limitaçóes que ele apresentava. A escola, cumprindo o papel de remover tudo isso, abriria espaço para o seu processo de inserção plena na civilização ocidental. Eu tenho chamado a tudo isso de um grande processo de desafricanização. É de um processo de desafricanização que nós estamos falando. Eu não sei qual era a posição do Dr. Anísio em relação a isso. Ainda não encontrei nada escrito por ele pessoalmente sobre o que pensava do negro, o que pensava do indígena, e o que pensava dessa nossa diversidade. Toda a proposta do Dr. Anísio Teixeira em relação à educação é no sentido de desenvolver ao máximo as capacidades de cada um individualmente. Como é que isso vai ser feito? Como, nesse processo, vai entrar a sua herança cultural? $\mathrm{Na}$ pesquisa sobre desenvolvimento e educação em que estou envolvida agora estou tentando lidar com esta questão porque é uma questão fundamental com a qual eu não lidei antes. A razão pela qual os estudos de comunidade surgem na Bahia não é de fácil resposta. $\mathrm{O}$ mentor de tudo isso, como eu já disse, é Anísio Teixeira. Se na sua concepção original ele já tinha pensado que o projeto se desenvolvesse em torno dos estudos de comunidade, eu não sei. Agora tendo convidado o Prof. Wagley e o Eduardo Galvão para esboçarem o pré-projeto, o encaminhamento dado por eles parece natural, dado seus envolvimentos em tais estudos. O Wagley entrou em contato com o Brasil muito cedo em sua trajetória acadêmica quando tinha acabado de se doutorar e estava ingressando no departamento de Antropologia da Universidade de Columbia. Nesse momento teve uma chance de vir ao Brasil numa missão americana e entrou em contato com o Museu Nacional e com Dona Heloísa Alberto
Torres. Foi via Museu Nacional que Wagley tomou contato com o Brasil. Galvão era indigenista do Museu Nacional e fez seu doutoramento com Wagley. Wagley casou-se com uma carioca de família bem posta na sociedade local. Então essas redes vão se formando e tudo isso está acontecendo no Rio de Janeiro. Em que momento o Dr. Anísio entra em contato com Wagley, eu ainda não sei. Mas, quando ele pensa o projeto da Bahia, ele confere ao Charles Wagley uma posição bastante privilegiada, o que nos permite pensar numa relação já bastante consolidada. Então, como diretores do projeto são convidados o professor Charles Wagley, o Dr. Thales de Azevedo (que é antropólogo e médico da Secretaria de Saúde) e o Professor Costa Pinto que é da Universidade do Brasil. A relação com o Costa Pinto já não é via Museu Nacional, é via Universidade do Brasil e, talvez, via Arthur Ramos, que a essa altura está na UNESCO, de onde Costa Pinto está voltando para o Brasil, Costa Pinto que foi aluno querido e respeitado de Arthur Ramos. Você vê como as coisas se dão? Então é um mundo assim de relaçóes a partir das quais os interesses profissionais vão se estruturando, vão tomando forma, ganhando cara de projeto, etc.

\section{CC: Como se dá a passagem do Programa} Estado da Bahia - Columbia University para o projeto UNESCO?

JC: Quando o Marcos Chor Maio5 começou o trabalho dele, ele tinha a ideia de que o projeto UNESCO foi "o" grande projeto, foi o primeiro projeto. Mas náo foi o primeiro projeto de pesquisa na área de ciências sociais que o Brasil conheceu. Há esses dois projetos que são anteriores, o de São Paulo e o nosso. Quando o Metraux chegou com o projeto da UNESCO em janeiro de 1951 na Bahia, já fazia seis meses que nós estávamos em campo. Ele chega com aquela proposta maravilhosa de 
estudo das relaçóes raciais. Claro, todo mundo ficou encantado e cada um dos três rapazes [Marvin Harris, Harry Hutchinson e Benjamin Zimmerman] ficou encarregado de dedicar uma atenção especial às relaçóes raciais.

\section{CC: E antes não havia essa atenção especial} ao estudo das relaçóes raciais?

JC: Não, não havia. Em Rio de Contas, por conta das especificidades de suas relaçôes raciais, a questão racial tinha aparecido de cara no trabalho de Marvin Harris. Porque, lá, as relações entre pretos e brancos eram críticas. Mas isso era uma característica da sociedade riocontense. E, necessariamente, apareceria no trabalho de Marvin Harris. Mas, as relações raciais como um tópico específico da pesquisa acabou se tornando comum a partir do projeto da UNESCO. Tanto que a primeira publicação que se faz do projeto da Bahia é sobre as relaçôes raciais e é financiada pela UNESCO - que é o trabalho Race and class in rural Bra$z i l^{6}$, aquela coletânea que o Professor Wagley organiza, incluindo três capítulos referentes às comunidades baianas e um capítulo sobre Itá, que é a comunidade amazônica que ele tinha estudado antes, juntamente com Eduardo Galvão. Isso foi em 1952 quando sai a primeira publicação resultante do estudo da UNES$\mathrm{CO}$ abordando as comunidades estudadas na Bahia. O trabalho do Dr. Thales [de Azevedo], As elites de cor numa cidade brasileira ${ }^{7}$, saiu primeiro em francês no ano seguinte, em 1953 e só depois saiu em português.

CC: Em sua opinião, como a Bahia foi se tornando tão central para os estudos de comunidade e para as ciências sociais neste determinado momento?

JC: Eu não posso te dizer como, porque ainda não sei. $\mathrm{Na}$ verdade, estou agora voltando a essa época. O Programa de Pesquisas Estado da Bahia - Universidade de Columbia, que realizou três estudos de comunidade no primeiro ano e mais um no segundo ano, foi fruto da iniciativa de Anísio Teixeira que desejava através destes estudos aprofundar o conhecimento da realidade interiorana da Bahia para subsidiar a sua gestão como Secretário. A questão é saber o que levou a isto. Há muitos aspectos a serem investigados neste sentido. Quem fez um trabalho muito bonito utilizando o conceito de rede no Rio de Janeiro, tentando mostrar como o Arthur Ramos faz parte de uma imensa rede e como essa rede é fundamental para o desenvolvimento das ciências sociais no Brasil foi o Luitgarde Cavalcanti ${ }^{8}$. Anísio é baiano, Arthur Ramos é alagoano, fez medicina na Bahia e dá continuidade à obra de Nina Rodrigues. Quem aproxima Arthur Ramos de Anísio Teixeira é outro baiano, o Afrânio Peixoto - que é baiano de Lençóis, que é um lugar onde o pai de Anísio Teixeira vai se casar três vezes, com três irmãs: uma morre; ele casa com a segunda, essa morre; ele se casa com a terceira que vai ser a mãe de Anísio Teixeira. Quanto aos estudos de comunidade é importante dizer que no final dos anos de 1940 na Universidade de Columbia eles vivem um verdadeiro "boom". O primeiro estudo deste gênero não foi feito por antropólogos, mas os antropólogos se encantaram com a ideia e logo assumiram com muita paixão essa modalidade de estudos, dadas possibilidades que essa modalidade oferecia de estudos das sociedades complexas. O primeiro estudo de comunidade, pelo menos tido como tal, intitulado Middletown, é de um sociólogo americano $^{9}$ - vocês já devem ter ouvido falar disso. Outra figura muito importante é o Robert Redfield, de Chicago. A partir do trabalho dele em Yucatán ${ }^{10}$ com quatro comunidades ele constrói o conceito de gradiente, partindo de uma comunidade indígena até uma comunidade na costa, que é uma comunidade urbana. Ele toma essa sequência como um gradiente e 
sua tese consiste em mostrar que quanto mais a comunidade se aproxima do litoral, mais urbana ela se torna, menos indígena, etc. Esta é uma tese que o Marvin [Harris] vai contestar em seu doutorado elaborado a partir da pesquisa em Rio de Contas. Porque Rio de Contas está a $600 \mathrm{~km}$ de Salvador e não poderia ser mais urbana. Então, são questôes como estas que estão sendo postas naquele momento e têm muito a ver com os interesses da Antropologia, com a intenção dos antropólogos em se aproximarem das sociedades complexas, ao procurarem essa via dos estudos de comunidade. Eu gostaria de ter tido mais maturidade na ocasião para ser capaz de perceber tudo isso, mas com o tempo você vai acordando para todas essas conexôes e fica se perguntando: afinal que relação tem tudo isso com o desenvolvimento das ciências sociais? Mas não só com o desenvolvimento das ciências sociais, mas com a relação da educação com as ciências sociais ou das ciências sociais com a educação. Uma relação que até hoje é muito pouco explorada, pouco trabalhada.

CC: Mas os estudos de comunidade não eram parte de um projeto civilizatório? Assim, o interior da Bahia naquele exato momento visto por Arthur Ramos em pleno processo de africanização não seria o melhor laboratório para se fazer um estudo como esse?

JC: Não consta do projeto inicial do Programa de Pesquisas Sociais do Estado da Bahia - Columbia University nenhuma preocupação especial com a questão étnica. A preocupação era conhecer a realidade rural do estado da Bahia para subsidiar o planejamento das ações do Secretário de Educação e Saúde [Anísio Teixeira]. Era um projeto voltado para pesquisa da realidade social, cultural, econômica, cultural, política, etc, a serviço do planejamento em educação. Então, o interesse pela pesquisa tinha muito a ver com o pensamento do Anísio. Ou seja, o interesse em pensar o seu plano de trabalho com base num conhecimento científico da realidade. Uma das coisas em que tenho pensado no projeto atual é sobre o tipo de conhecimento que havia então sobre a realidade do interior do estado. Anísio Teixeira foi criado na região de Caetité, o pai dele era um rico coronel; Anísio Teixeira era um homem de elite e tinha conhecimento dessa realidade interiorana. Depois ele vai para o exterior, volta e assume a Diretoria Geral da Instrução no Rio de Janeiro e vai ampliando cada vez mais seu conhecimento dessa realidade. Mais tarde, como Secretário da Educação e Saúde, ao mesmo tempo em que ele vai se tornando um grande nome ligado à educação, também vai se envolvendo com o mundo político, um mundo que tem um conhecimento próprio da realidade, seja interiorana, seja urbana. Como Secretário da Educação ele vai ter acesso a muitas vias de conhecimento do interior de seu estado. Mas onde estavam os dados objetivos sobre esta realidade? Os censos não eram bons. Acho que não houve censo em 1930, houve o de 1940 feito já em outro patamar pelo IBGE, que foi criado para realizá-lo. Foi o primeiro grande censo importante feito de acordo com especialistas. Antes disso, os dados não eram tão confiáveis assim. Esse país era um país eminentemente rural. A maioria da população estava no campo. Então, o que nós sabíamos a respeito desse campo? O que nos vinha através dos informes dos políticos, dos prefeitos, das autoridades de educação. Havia muita informação, mas se não tinha um estudo científico dessa realidade. A preocupação com o estudo científico tem a ver com a modernidade. Tem a ver com esse momento que está se constituindo depois da Segunda Guerra. Com o final da Segunda Guerra também caí a ditadura do Getúlio. E aí, enfim, se começa a pensar num novo Brasil; talvez por aí: a preocupação com "agora sim, a partir de 
agora nós precisamos pautar as nossas ações, o nosso planejamento sobre dados cientificamente fundamentados". Acho, que por aí, a gente pode entender o porquê. $\mathrm{O}$ fato do Anísio ter ido para a Bahia talvez seja realmente fundamental para responder a sua pergunta. Porque com a saída do Anísio, nada vingou. $\mathrm{O}$ Anísio deixa a Bahia e vai para o Rio de Janeiro em 1952 e cria uma Fundação para dar continuidade à pesquisa, ao projeto e essa Fundação tem uma vida muito efêmera, uma vida que se esvazia. A Fundação para o Desenvolvimento da Ciência na Bahia foi um órgão criado para dar continuidade ao Programa, ficar responsável pelas publicaçóes, responsável pela divulgação desse material e continuar daí pra frente a desenvolver um trabalho nessa área. Nada disso aconteceu. É verdade que dez anos depois você tem 1964. Mas, e nesses dez anos?

\section{CC: Como era a inserção das mulheres em campo?}

JC: Os primeiros a serem convocados foram os rapazes. Foram do Rio de Janeiro: Nilo Garcia e um rapaz com um nome muito inglês, Lincoln Alisson Pope. O Lincoln foi auxiliar da pesquisa no Sertão semi-árido do Ben [Benjamin] Zimmerman e o Nilo Garcia foi auxiliar do Marvin Harris na Chapada Diamantina. A primeira mulher a ingressar na equipe foi a Carmelita Junqueira Ayres, irmã do Jaime Junqueira Aires, amigo do Anísio, que era do setor jurídico da Secretaria da Educação. Carmelita Junqueira Ayres tinha feito História, acho que em uma faculdade do Rio e estava disponível. A comunidade que ia ser estudada no Recôncavo tinha uma ligação profunda com a família dela: São Francisco do Conde e a Usina São João, que era propriedade da família dela. Mais tarde ela se casaria com Bill [Harry Hutchinson]. Então as más línguas costumavam dizer que Bill Hutchinson fazia pesquisa do terraço da casa grande. Conjuntura mais auspiciosa ele não poderia ter encontrado. Primeiro, São Francisco do Conde era pertíssimo de Salvador. Segundo, o acolhimento que ele recebeu da família Junqueira Aires. Ele era aquele que a gente achava que tinha cara de americano, de americano típico. Fumava cachimbo, tinha um topetinho, era magrinho, de olhinho azul, sempre risonho, sempre bem humorado. $\mathrm{Pa}$ recia marinheiro. Sabe a figura do marinheiro? Vocês não são dessa época, não viram os cartazes de propaganda da segunda guerra aquele americano de gorrinho, de calça larga, olhinho azul. Os outros dois eram judeus e tinham tipos físicos e personalidades bem diferentes. Gizella Valladares era mulher do José Valladares, que era diretor do Museu do Estado. Era mulher americana, judia que tinha uma qualificação, não sei se em museologia. De qualquer modo, ela era alguém que estava sempre presente porque participava do mesmo mundo social e intelectual do Dr. Anísio. Ela aproximou-se muito do Ben Zimmerman, que foi quem estudou Monte Santo e foi ajudá-lo na sua pesquisa. Eu, Maria Raimunda e Nilda Guerra de Macedo, sua irmá, só entramos no projeto no final de 1950, nas férias, porque éramos estudantes. Nas férias de dezembro, Maria Raimunda e eu fomos para a Chapada Diamantina e Nilda foi para o Sertão. Eu acho que Carmelita e a Gizella começaram a ajudar desde o princípio, em razão da disponibilidade que elas tinham. Gizella tinha duas filhas, mas isso não devia atrapalhar. E Carmelita não estava trabalhando. Nós três éramos alunas de geografia e história na Faculdade de Filosofia e só podíamos ir nas férias. Agora, não era uma coisa tranquila para nós, três donzelas, irmos pro campo no final dos anos de 1950 trabalhar com esses americanos. No meu caso em particular, houve uma preocupação muito grande na minha família: "Como que essa menina vai sozinha lá táo longe? Se o pai dela fosse vivo não ia consentir!” Aquela admira- 
ção. Por fim, combinou-se que minha mãe iria me acompanhar. Vocês pensam que é assim? Como é hoje? Que a gente vai pra qualquer lugar? Minha mãe ia me acompanhar. Nesse meio tempo, porém, Maria Raimunda, minha amiga querida, teve uma desilusão amorosa muito grande e resolveu que a melhor forma de afogar essa mágoa era sair de Salvador. E como ela era tão aluna de Thales como eu em antropologia, uma excelente aluna, então caiu a sopa no mel. E no lugar da minha mãe, fomos nós duas. Foi assim que, nós mulheres, entramos nesse projeto. Sempre que eu vou a Rio de Contas eu procuro saber como Rio de Contas viu a presença dessas moças durante três meses fazendo trabalho de campo com o americano. Nós fomos inicialmente para uma pensão. O QG da pesquisa era na casa de Marvin [Harris]. Lá ele ficava com Nilo e nós ficávamos na pensão. Até o dia em que Raimunda achou que já estava na hora de acabar com essa brincadeira e nós podíamos (risos) mudar pro QG. Mas isso foi no último mês da pesquisa, (risos) depois que nós já éramos conhecidas e já não havia mais dúvida de que ninguém tinha envolvimento nenhum com ninguém. Além do que, havia uma empregada na casa e um dos informantes do Marvin era uma pessoa que não desgrudava da gente. Se houvesse alguma coisa, o Julinho seria o primeiro a botar a boca no mundo. Mas também aconteceu o seguinte: já no último mês da nossa estada por lá, em fevereiro de 1951, nós tivemos que ir para Mato Grosso, uma pequena localidade que fora importante na mineração do ouro e que tinha decaído muito, na medida em que o ouro desapareceu. E aí nós íamos ficar todos na mesma casa, não tinha mais jeito. Depois de Mato Grosso, Raimunda achou (e ela era muito atirada) que não faria mais sentido continuar pagando pensão e que a gente ia ficar de uma vez lá no QG da pesquisa. E eu também achei que tudo bem e, assim, foi.
CC: Como se dava a divisão do trabalho em campo entre homens e mulheres?

JC: Eu e Maria Raimunda, fomos justamente para cobrir a área feminina, como por exemplo: reprodução, toda a atividade reprodutiva. Pesquisar o comportamento reprodutivo para os homens era difícil, então caberia a nós. Toda a parte de educação das crianças, tudo o que envolvia conversa com mulher ficou por nossa conta. Foi para isso que nós fomos e acho que Nilda fez a mesma coisa lá em Monte Santo e Carmelita certamente com Hutchinson. Inicialmente, a gente não tinha muita clareza sobre isso e fomos orientadas pelo princípio de que tudo era importante e que nós tínhamos que prestar atenção a tudo. Mas a nossa tarefa específica era trabalhar com os assuntos femininos, essencialmente femininos.

CC: A senhora diz que a sua ida para a Escola de Sociologia e Politica foi uma preparação para a sua ida para a Universidade de Columbia. Como foi essa passagem? O contato com os professores estrangeiros e o contato com outra tradição de estudos de comunidade que estavam sendo feitos em São Paulo, coordenados pelo Donald Pierson?

JC: Quando eu vim para a Escola, as coisas todas se encaixaram. Eu havia terminado o bacharelado no final de 1951. Ajudara na pesquisa do Marvin [Harris] na Chapada Diamantina em 1950 e no ano seguinte na de Anthony Leeds, na zona do cacau ao mesmo tempo em que concluia o terceiro ano. Então o Tony resolveu pedir para o Dr. Anísio que eu estendesse minha permanência no campo, mas eu pretendia fazer a licenciatura. Aí ficou aquele impasse: "bem, mas você em lugar da licenciatura pode ir pra Escola de Sociologia e Política”. Como a Sociologia e Política tinha um currículo bastante flexível eu não precisaria ir em março, eu poderia deixar pra ir no meio do ano. $\mathrm{O}$ que na verdade fazia muito 
mais sentido porque Columbia só ia começar em setembro de 1953. E assim, eu voltei pro campo na zona do cacau no primeiro semestre de 1952. E no incío do segundo semestre (dia 31 de julho), eu vim para São Paulo. São Paulo foi uma experiência nova e ampliada de vivência urbana e vivência de relaçôes raciais. Eu saí da Bahia para São Paulo, a caminho dos Estados Unidos (onde a segregação racial era total, absoluta), e então era importante que eu fosse me preparando pra qualquer eventualidade, pra ser discriminada, etc. E foi assim que eu vim pra São Paulo pra completar os meus estudos, já que eu precisava de quatro anos pra ir pra Columbia. Mas também para viver uma outra experiência: urbana, de grande cidade e de outras relaçóes raciais. Este contexto de outras relações raciais não era falado, não era mencionado, mas era um subtexto mais ou menos perceptível. E eu vim para São Paulo e foi muito bom.

CC: Quando a senhora chegou, Donald Pierson já havia se afastado da Escola de Sociologia e Politica?

JC: Quando eu cheguei ele já não estava na Escola porque ele havia adoecido e passava vários períodos nos Estados Unidos. No primeiro semestre de 1952 ele não estava na Escola. Eu vim a conhecê-lo no ano seguinte, muito rapidamente. Eu não cheguei a fazer nenhum curso com ele porque ele estava neste processo de tratamento.

CC: E como foi sua passagem pela Universidade de Columbia e os cursos de verão na Universidade de Chicago?

JC: Columbia foi a realização de um sonho. Columbia foi tudo de bom que eu poderia ter experimentado naquele momento na minha vida. Uma universidade de primeiro mundo, em uma cidade como Nova Iorque. Você pode imaginar as oportunidades de cres- cimento intelectual, pessoas, experiências que eu pude viver lá em todos os níveis. Com os colegas, eu conhecia gente de todo lugar do mundo. Vim a dominar uma outra língua, conhecer professores que eram muito qualificados em suas áreas. Ouvir, falar, estudar coisas que eu realmente não tinha oportunidade de estudar nem na Bahia, nem em São Paulo. A gama de oportunidades era muito grande, conhecer museus, lugares, cinema, teatro. Foram dois anos muito intensos. Eu tinha uma bolsa da CAPES que era renovada a cada semestre. Não fui com uma bolsa de doutorado pleno, eu fui numa condição muito precária para quem vai fazer um doutorado. Ninguém me disse claramente que eu estava indo para fazer um doutorado. Eu estava indo porque era uma promessa e fizera por merecer, tinha mostrado que era bom que se investisse em mim. Assim, eu recebi inicialmente uma bolsa de seis meses, renovada por mais seis, por mais seis, por mais seis. Então eu fui dando o máximo de mim a cada semestre, fui me atolando de cursos, uma loucura, para poder fazer o máximo que eu pudesse no tempo de que eu dispunha. E foi assim que eu consegui completar todos os créditos do doutorado, fazer todos os exames e, no final de dois anos, voltar pra fazer a pesquisa de campo com vistas ao doutorado - que era o que eu queria fazer. Por outro lado, dois anos era o tempo de que eu dispunha para ficar afastada do serviço público. Porque eu era dos quadros do professorado de Salvador. Eu poderia ficar afastada dois anos, não mais do que isso. Então tudo isso somado, no final de dois anos, eu voltei. E foi aí que eu causei uma grande decepção ao Dr. Anísio. Porque eu voltei com um projeto de pesquisa que náo interessou a ele. $\mathrm{O}$ projeto dele, por outro lado, também não me interessou. Porque eu não tinha nenhum interesse em trabalhar com educação naquele momento. Eu queria ir para o campo e fazer minha pesquisa. E queria 
voltar para Columbia e fazer meu doutorado. Eu achava que tudo que eles tinham me mostrado até entáo sinalizava o meu doutoramento na Universidade de Columbia. Mas só eu achava isso, porque eles não achavam. Carmelita havia ido e não conseguira. Ela não conseguiu nem dominar o inglês. Ela entendia tudo, mas não conseguia falar. Era uma limitação, um bloqueio

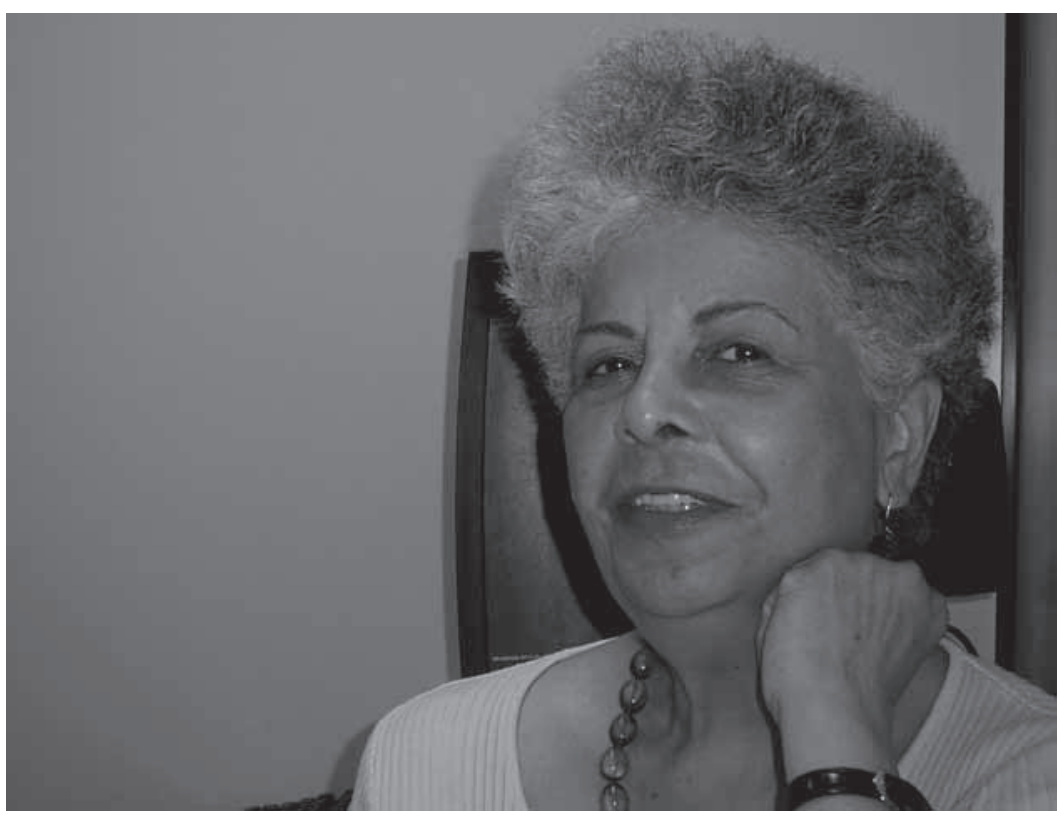
extraordinário. Ela foi antes de mim, estudou, fez vários créditos, mas não conseguiu, casouse com Bill e desistiu dos estudos. Mas para mim era muito claro que eu estava lá pra fazer pós-graduação e fazer o doutorado. Os de lá me diziam isso, e me incentivavam nessa direção. Lá estavam o Tony Leeds, o Marvin, o Wagley. Todos que eu tinha ajudado tanto aqui. Mas não deu certo. Voltei com os créditos de disciplina e os exames de língua, os exames finais. Mas o Dr. Anísio não estava interessado no meu projeto. Estava interessado em criar o Centro Brasileiro de Pesquisas Educacionais [CBPE], que é o que eu considero o terceiro momento dele [de Anísio Teixeira] de aproximação das ciências sociais, e o mais importante. Contar com a participação do Arthur Ramos, na década de 1930, como Diretor Geral da Instrução no Rio de Janeiro até constituir o projeto nos anos 50 na Bahia foram avanços em termos de aproximaçáo das ciências sociais. A criação de um Centro de Pesquisas Educacionais, porém era algo muito maior. E era isso que ele queria criar em 1955, o Centro Brasileiro de Pesquisas Educacionais.

Tinha esse título de Pesquisas Educacionais, mas era totalmente voltado para educação e ciências sociais. A revista que o Centro editava se chamava "Educação e Ciências Sociais". O Centro se estruturou em duas divisôes: uma divisão de pesquisas sociais e outra de pesquisas educacionais. Darcy Ribeiro foi um dos diretores da divisão de pesquisas sociais e Jaime Abreu, um antigo colaborador do Dr. Anísio vindo da Bahia, onde tinha sido diretor das pesquisas educacionais. O Centro sempre trabalhou buscando articulação entre estas duas vertentes fazendo coisas muito importantes, projetos enormes envolvendo grandes nomes. Um deles se chamou "Urbanização e Industrialização" e envolveu Eunice Durham, Mário Vagner [Vieira da Cunha], Florestan [Fernandes], Fernando Henrique [Cardoso], Octávio Ianni, Luiz Pereira, Carolina Martuscelli Bori (da Psicologia Social), Aniela Ginsberg, Juarez Brandão Lopes, Oracy Nogueira, Arrigo Angelini, Aparecida Joly Gouveia, entre outros. O CBPE tinha dinheiro e a universidade tinha os recursos humanos, e, foi aquele casamento. A caminho da cidade $^{11}$, de Eunice Durham, por exemplo, foi fruto do projeto "Urbanização e 
Industrialização”. O CBPE foi uma instituição muito importante e funcionou como um braço direito do INEP [Instituto Nacional de Estudos e Pesquisas Educacionais]. O CBPE foi criado para realizar aquilo que o INEP não tinha conseguido realizar. E o Dr. Anísio, como diretor do INEP, criou o CBPE para realizar as pesquisas que o INEP não estava conseguindo realizar.

\section{CC: E quando a senhora volta dos Estados} Unidos, afirma que as ciências sociais no Brasil se modificam, por exemplo, não havia mais interesse nos estudos de comunidade e mesmo o seu direcionamento de carreira se modifica. Enfim, no que consiste essa mudança, tanto nas ciências sociais do Brasil, quanto nos Estados Unidos?

JC: Mudou sim, mesmo em Columbia. Columbia havia sido a grande expressão do culturalismo. O culturalismo nasceu em Columbia pelas mãos de Franz Boas e foi a vertente dominante do pensamento da antropologia até o início dos anos de 1940. Nos anos 40 o que você encontra em Columbia já é a crítica muito forte a [Franz] Boas. Essa crítica a Boas vai representar uma abertura de espaço pra outras influências. Aí entram os estudos de comunidade e depois entra o neoevolucionismo do Leslie White. Quando eu chego em Columbia, a vertente mais expressiva, mais importante do pensamento na antropologia era o neoevolucionismo. O neoevolucionismo com Morton Fried, com Marshall Sahlins (que estava fazendo o seu doutorado lá), com Marvin Harris, como o próprio Anthony Leeds. Era o que se discutia e funcionava como uma grande crítica ao culturalismo, na medida em que o neoevolucionismo retomava a grande história. Num momento em que se precisava pensar novamente a grande história. Quando eu voltei para o Brasil, em 1955, Darcy Ribeiro estava no Museu do Índio e tinha acabado de montar um curso de especialização. Depois da Escola de Sociologia e Política esse era o primeiro curso voltado para pós-graduandos, entre nós. O curso do Darcy no Museu do Índio era um curso para formação de pesquisadores também financiado pela CAPES, pelo Dr. Anísio. Formou várias turmas e a orientação teórica do curso era o neoevolucionismo. Esse curso acabou sendo levado para o CBPE quando o Darcy se incompatibilizou com o Museu do Índio. Foi entáo que ele se tornou diretor da Divisão de Pesquisas Sociais do CBPE. Abandonou a carreira de indigenista e aderiu à educação, pela qual ele antes não se interessava. Antes ele dizia para mim quando eu estava no CBPE e, ele, no Museu do Índio: "O que você está fazendo lá? Deixa isto para lá. Educação é muito chato”. Costumávamos ir à casa dele no final de semana. Ele morava na zona norte, na Boca do Mato. Era tudo muito simples no Rio de Janeiro daquela época.

\section{CC: Quando a senhora regressa ao Brasil não} volta para São Paulo?

JC: Eu queria voltar pra São Paulo ou pra Bahia. Mas não consegui nem uma coisa, nem outra. E o Dr. Anísio, que era quem podia me abrir as portas, abriu efetivamente, mas abriu para que eu viesse trabalhar no projeto dele, não no meu projeto. E eu demorei muito pra aceitar isso. Eu fui como quem vai pro cadafalso. Porque eu não queria trabalhar na área de educação, então eu fui porque eu precisei ir, mas acabei me envolvendo profundamente com ela. época?

CC: Qual era seu projeto de pesquisa nesta

JC: Eu queria fazer um estudo no norte do Paraná. Eu queria ver que Brasil estava surgindo no norte do Paraná, a partir de diferentes matrizes - os nordestinos que estavam indo para lá e os descendentes dos colonos que tinham ocupado aquela região. Era isso o que 
eu queria ver. Tinha tudo a ver com tudo que eu havia feito antes. No interior da Bahia eu tinha visto a migraçáo interna, as cidades todas esvaziadas porque a população, os homens estavam todos indo para o sul e para o Paraná. E o norte do Paraná era onde a colonização estrangeira tinha uma importância muito grande. Eu queria ver o que era isso. Que Brasil era esse. Provavelmente eu ia fazer um outro estudo de comunidade. Não tinha nada a ver com o que ele estava querendo naquele momento. Ele estava querendo criar o CBPE, um Centro de Estudos poderoso, onde as ciências sociais pudessem mais uma vez ajudar a educação a pensar, a crescer.

CC: O fato de a senhora não ter conseguido levar adiante o projeto de pesquisa que pretendia inicialmente não está relacionado com a perda de interesse dos estudos de comunidade no Brasil?

JC: Você tem toda a razão. Eu acho que as coisas têm voga, entram em moda e saem de moda. Tinha passado o momento dos estudos de comunidade, mas havia ainda alguns estudos sendo realizados. Eu voltei em 1955, os estudos de comunidade continuaram até a década de 1960. O [Octávio] Ianni ${ }^{12}$ fez uma avaliação dos estudos de comunidade e o Oracy Nogueira $^{13}$, que foi um grande estudioso desta área, também fez. E é uma avaliação tão boa quanto a do Ianni, ambos incidem sobre os mesmos pontos, mas com diferentes abordagens. E eu, em um evento em homenagem ao Ianni, escolhi fazer uma avaliação de estudos de comunidade. Então eu fiz uma avaliação destas duas posiçôes para chegar à minha explicação do porquê os estudos de comunidade tinham realmente perdido o interesse. Mas, quando eu voltei de Columbia eu não tinha esta clareza de que os estudos de comunidade tinham perdido a sua vez, tinham passado de moda. Já não davam conta da realidade como se esperava que eles pudessem dar. Era um outro Brasil, realmente era um outro Brasil. O Brasil de 1955 era uma outra coisa, com o desenvolvimentismo toda a preocupação era com os processos de crescimento urbano, de industrialização, não era com os estudos micro, com os estudos locais. Este Brasil dicotômico tinha ficado para trás. $\mathrm{O}$ que se queria entender agora era o processo de urbanização e industrialização, era o que estava acontecendo nas grandes cidades porque a problemática tinha se transferido para as grandes cidades, para as cidades de um modo geral. O que eu vou encontrar no Rio de Janeiro (na segunda metade da década de 1950) é um crescimento enorme da população favelada, um imenso problema do sistema educacional em lidar com esta criança que vem das favelas. Quer dizer, o "outro" não é mais o homem rural, o "outro" é o favelado. Isso é o Rio de Janeiro em 1955. E vai ser São Paulo um pouco mais tarde também. A criança favelada, a criança da periferia é a que vai se constituir em problema para a escola ${ }^{14}$.

CC: Em seu artigo ${ }^{15}$ na coletânea sobre o Ianni, a senhora ao falar dos estudos de comunidade faz um comentário sobre o interesse dos pesquisadores pelo destino das comunidades, pelo planejamento das intervençóes, indicando a presença de certo ideal de reforma social, de uma pesquisa engajada. Os dados deveriam subsidiar as intervençóes, os programas. Como isso se dava?

JC: De fato, havia sim. Todos os que se envolveram com estudos de comunidade estavam absolutamente convencidos de que estavam fazendo o trabalho que precisava ser feito naquele momento. Existe, por exemplo, uma série de estudos que foram feitos no Rio de Janeiro por Dona Heloísa Alberto Torres em Cabo Frio, um programa de que nunca mais ouvi falar, que foi enorme, totalmente voltado para os estudos de comunidade. Houve também uma preocupaçáo muito grande de estudos de co- 
munidade por parte da área da saúde. A repercussão dos estudos de comunidade foi muito grande. Depois, o que aconteceu? Para começo de conversa, nem todos foram publicados. Há um problema muito grande em tudo isso que é o da descontinuidade das administraçóes. Os projetos são desenvolvidos por uma administração, a administração seguinte não dá continuidade. É como se aquilo ficasse como letra morta, e não tivesse nenhuma importância porque a preocupação da administração seguinte já é outra. E, assim, as coisas vão caminhando. Quando eu cheguei no CBPE, o primeiro trabalho que me deram foi avaliar a contribuição que os estudos de comunidade tinham dado ao conhecimento dos problemas de educação. Tive que cortar na própria carne porque era preciso avaliar coisas de que eu tinha participado e dizer que, infelizmente, o que estes estudos, inclusive aqueles de que eu participara e que foram direcionados para oferecer subsídios à área da educação, pouco tinham se interessado pela educação. Os outros, que não tinham tido esse objetivo, menos ainda. Então a área da educação era uma área realmente muito pouco levada em consideração nos estudos de comunidade. No geral, a economia era bem coberta, política, um pouco de família, organização social, etc. Mas educação e saúde eram áreas praticamente intocadas nesses estudos. O que resultou desses estudos? Essa é uma pergunta que nós continuamos nos fazendo: o que efetivamente resultou, além do conhecimento que eles revelam desse Brasil, do Brasil daquele momento? Em termos de subsídios para planejamento, para uma intervenção, para transformação social, eu acho que nada. A dinâmica de cada comunidade, o modo como ela se inseriu dentro deste processo desenvolvimentista é que acabou dando o tom das mudanças.

\section{Notas}

1 Ver depoimento de junho de 1994 concedido a Niuvenius Junqueira Paoli, para sua tese de doutorado As Relaçôes entre Ciências Sociais e Educaçâa nos anos 50/60, defendida em 1995, na Faculdade de Educaçáo da Universidade de Sáo Paulo. A tese tem como foco a trajetória e produção intelectual de quatro personagens: Josildeth Gomes Consorte, Aparecida Joly Gouveia, Juarez Brandáo Lopes e Oracy Nogueira.

2 A Escola Normal era oferecida em nível secundário (equivalente ao ensino médio) e seu objetivo era formar professores para o magistério do ensino primário (hoje, fundamental). A formação em Escola Normal limitava o ingresso no ensino superior apenas à área de humanidades. Para outras áreas, era necessário ter cursado os chamados cursos "clássicos" ou "científicos".

3 Atualmente Josildeth Consorte coordena na PUC/ SP (Pontifícia Universidade Católica de Sáo Paulo) uma pesquisa sobre desenvolvimento nacional e educação. A pesquisa, que revisita os estudos realizados pelo Programa de Pesquisas Sociais do Estado da Bahia e Universidade de Columbia, é fruto de um convênio firmado entre quatro universidades: PUC/ SP, UESB (Universidade Estadual do Sudoeste da Bahia), Unicamp (Universidade Estadual de Campinas), e UNEB (Universidade do Estado da Bahia).

4 Segundo Josildeth Consorte, Anísio Teixeira tem uma marcante aproximaçáo com as Ciências Sociais em três momentos distintos: em seu primeiro contato como Diretor Geral da Instrução com Arthur Ramos nos anos 1930, na formulação do Programa de Pesquisas Sociais do Estado da Bahia e na criaçáo do CBPE - Centro Brasileiro de Pesquisas Educacionais.

MAIO, Marcos Chor. A História do Projeto UNESCO: Estudos Raciais e Ciências Sociais no Brasil. Tese (Doutorado em Ciência Política) - IUPERJ, Rio de Janeiro, 1997.

6 Wagley, Charles ed. 1963. Race and Class in Rural Brazil. Paris: UNESCO.

7 Publicado originalmente como Les élites de couleur dans une ville brésilienne. Paris: UNESCO, 1953. Ediçôes em português sob os títulos As elites de cor: um estudo de ascensáo social. Rio de Janeiro: Cia. Editora Nacional, 1955. [Sé- 
rie Brasiliana]; e As elites de cor numa cidade de brasileira \& Classes sociais e grupos de prestígio. Salvador: EDUFBA/EGBA, 1996.

8 BARROS, Luitgarde Oliveira Cavalcanti. Arthur Ramos e as dinâmicas sociais de seu tempo. Maceió: EDUFAL, 2000.

9 O trabalho foi realizado, em 1929, por Robert Lynd e Helen Lynd em uma pequena cidade dos EUA, chamada pelo nome fictício de Middletown.

10 Robert Redfield realizou várias pesquisas em Yucatán, no México. A pesquisa deu origem a diversos trabalhos, entre eles The Folk Culture of the Yucatan, de 1941.

11 DURHAM, Eunice. A caminho da cidade. São Paulo: Perspectiva, 1973.

12 IANNI, Octávio. Estudo de Comunidade e Conhecimento Científico. Revista de Antropologia, vol.9, n., 1-2, 1961, p.109-119.

13 NOGUEIRA, Oracy. Os Estudos de Comunidade no Brasil. Revista de Antropologia, vol.3, n.22, 1955, p. $95-103$.

14 Essa reflexão pode ser encontrada em seu estudo: CONSORTE, Josildeth Gomes. A criança favelada e a escola pública. Revista de Educação e Ciências Sociais, vol.5, n.11, p.45-60, 1959.

15 A citação refere-se a CONSORTE, Josildeth Gomes. Os estudos de comunidade no Brasil: uma viagem no tempo. In: FALEIROS, Maria Izabel. e CRESPO, Regina Aída. (Orgs.) Humanismo e Compromisso: ensaios sobre Octávio Ianni. São Paulo: Unesp, 1996.

\section{Agradecimentos}

O texto da entrevista é aqui apresentado com algumas modificaçôes das autoras, tais como, a inserção de notas explicativas e informaçôes que aparecem entre colchetes ao longo do texto, além de outras adequaçóes da linguagem oral para o texto escrito. As autoras agradecem, em especial, à professora Josildeth Consorte pela entrevista. E também a Adriano Ropero pela revisão técnica e apoio na transcrição e edição do texto.

\section{autoras Érika Figueiredo}

Doutora em Antropologia Social/Unicamp

Isabela Oliveira

Doutoranda em Ciência Social (Antropologia Social)/USP

Janaína Damasceno

Doutoranda em Ciência Social (Antropologia Social)/USP

Recebido em 20/11/2008

Aceito para publicação em 30/11/2008 